\title{
Quality of life of type 2 diabetic patients in Erbil city
}

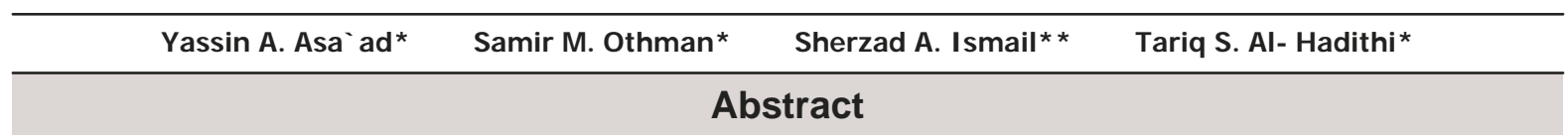

Background and objective: Diabetic patients could be at increased risk of functional disability, which needs good control of blood glucose and other risk factors and the quality of life of diabetic patients especially those who had complications is remarkably lower than the quality of life of the general population. This study was conducted to assess the quality of life of diabetic patients in its different domains from the patient's perspective in Erbil city. Methods: In this cross-sectional study, 160 diabetic patients were randomly selected from Layla Qassim diabetic health center. The WHO (WHO QOL- BREF) questionnaire was used as the main tool for data collection, which included26 questions on four domains of health-related quality of life (physical, psychological, social and environmental domains).

Results: Around $49 \%$ of the patients had checked their blood sugar regularly and had better scores in the social domain $(P=0.036)$. Diabetic patients of all age groups had low scores in all domains of quality of life, with the lowest mean score in the psychological domain. Females reported significantly higher scores in the environmental domain $(P=0.001)$. Patients with insufficient monthly family income had lower scores in the social $(P=0.001)$, psychological $(P=0.031)$ and environmental $(P=0.039)$ domains. There was no obvious statistical association between clinical characteristics of the patients and the quality of life domains. However, those with complications had lower scores in the psychological domain, with a higher proportion $(P=0.016)$ of complications in females.

Conclusion: All domains of quality of life are affected by diabetes mellitus, with no clear, consistent statistical association between clinical characteristics of the patients and the quality of life of various domains, which emphasize the need for more multidisciplinary team action for more patient's education and self-care.

Keywords: Quality of life; Diabetes; Social domain; Erbil; Iraq.

\section{Introduction}

Diabetes mellitus is a reason for an increasing public health alarm globally. Worldwide, the number of patients with diabetes probably would be double between 2000 and 2030,whilecommunity awareness regarding this disease remains low. ${ }^{1-5}$ The risk of diabetes continues to increase globally due to population expansion, urbanization, aging, and the growing prevalence of sedentary lifestyle practices and obesity. ${ }^{2,6}$ Data from International Diabetes Federation (IDF) show that the Middle East and North Africa (MENA) region has the highest incidence of diabetes worldwide. In this region nearly $12.5 \%$ of individuals aged $20-79$ years or 32.8 million individuals had diabetes in2011 and probably to be doubled in less than20 years. ${ }^{7-8}$ Diabetic patients could be at increased risk of functional disability that needs good control of blood glucose and other risk factors. ${ }^{9,10}$ Several studies have demonstrated that the quality of life (QOL) of patients with diabetic especially those who had complications is remarkably lower than the QOL of the general population. ${ }^{11,12}$ However, nearly all the researches on diabetes and health-related QOL were conducted in industrial

* Department of Community Medicine, College of Medicine, Hawler Medical University, Erbil, I raq.

** Kurdistan Board of Medical Specialties, Erbil, I raq. 
countries, while in developing countries are scarce. ${ }^{2,8}$ Variables such as age, sex, level of education, employment, body weight, could have impacts on patients with diabetes. ${ }^{11,13}$ The increasing rate of diabetes globally, particularly in the MENA region and scarcity of studies on $\mathrm{QOL}$ of diabetic patients at the national level and Kurdistan region, ${ }^{14,15}$ provided the impetus for assessing the QOL in a group of diabetic patients. This study was carried out to evaluate the QOL of diabetic patients in its different domains from the patient's perspective in Erbil city and to determine its relationship with certain socio-demographic and clinical characteristics.

\section{Methods}

A cross-sectional study was conducted in Erbil city, the capital city of Kurdistan region of Iraq, which is currently inhabited by $1,750,000$ populations. ${ }^{16} \mathrm{~A}$ systematic random sampling technique was used to select 160 patients with diabetes registered at Layla Qasim diabetic health center in Erbil city, by choosing every fifth patient attending the outpatient clinic of the health center. Data collection extended from $20^{\text {th }}$ of January 2016 to $10^{\text {th }}$ of February 2016. The World Health Organization, QOL (WHO QOL- BREF) questionnaire was used as the main tool for data collection. ${ }^{17}$ The questionnaire included questions on socio-demographic characteristics of the respondents, duration of the disease, frequency of blood sugar testing and presence of complications in addition to 26 questions on four scored domains ( 7 for physical, 6 for psychological, 3 for social and 8 for environmental domains) and two individually scored items about an individual's overall perception of quality of life and health. All the items were calculated on the five-point Likert scale, and all the domains were measured in a positive direction. Higher scores indicate better QOL; those who got 4 or 5 in the Likert scale have good QOL. Accordingly, those with $104(26 * 4=104)$ scores and more had good QOL. The questionnaire was tested on ten diabetic individuals as a pilot test prior to the actual survey to determine its validity. Patients aged 26 years and more from both sexes with a history of the disease for more than one year were included in the study. Those with gestational diabetes and those included in the pilot study were excluded. The data was collected by direct interview and the approximate interview time was between 20- 25 minutes. Data on blood sugar levels and glycemic control were obtained from patients' records and files. The study protocol was approved by the research ethics committee of the College of Medicine, Hawler Medical University. Collected data were entered into excel sheet and the statistical package for the social sciences (version 18.0) was used for data analysis. Chi-Square and t-test were used to determine the association between different categorical variables and mean scores. A $P$ value of $\leq 0.05$ was considered statistically significant.

\section{Results}

A total of 160 patients with diabetes were enrolled in the current study; their age ranged from 26 to 85 years, with a mean age $\pm S D$ of $53 \pm 12$ years. Nearly $60 \%$ of them were $50 y e a r s$ and older. Among the respondents, 92 (57.5\%) were females with a male to female ratio of $0.74: 1$. Other socio-demographic characteristics of the patients are presented in Table 1. The overall mean \pm SD scores of all the domains of QOL was $47.98 \pm 6.7$, with a median of 49.55 . Diabetic patients ( $<50$ and $\geq 50$ years) had low scores in all domains of QOL, with the lowest mean score in the psychological domain. Similarly, the psychological domain in both genders had the lowest scores. Females reported a significantly higher score in the environmental domain $(P=0.001)$. QOL of diabetic patients with insufficient monthly family income had lower scores than those with enough or more than enough family 
income in the social $(P=0.001)$, environmental $(P=0.039)$ domains psychological $(P=0.031)$ and (Table 2).

Table 1: Socio-demographic characteristics of the diabetic patients.

\begin{tabular}{|c|c|c|}
\hline Variables & No. & (\%) \\
\hline \multicolumn{3}{|l|}{ Age groups } \\
\hline 26- 49 years & 65 & $(40.6)$ \\
\hline$\geq 50$ years & 95 & $(59.4)$ \\
\hline \multicolumn{3}{|l|}{ Sex } \\
\hline Male & 68 & $(42.5)$ \\
\hline Female & 92 & $(57.5)$ \\
\hline \multicolumn{3}{|l|}{ Residence } \\
\hline Urban & 131 & (81.9) \\
\hline Rural & 29 & $(18.1)$ \\
\hline \multicolumn{3}{|l|}{ Education } \\
\hline Illiterate & 76 & $(47.5)$ \\
\hline Primary school education & 33 & $(20.6)$ \\
\hline Secondary school education & 30 & $(18.8)$ \\
\hline High education * & 21 & $(13.1)$ \\
\hline \multicolumn{3}{|l|}{ Monthly Family income } \\
\hline Not enough & 21 & $(13.1)$ \\
\hline Enough & 106 & $(66.3)$ \\
\hline More than enough & 33 & $(20.6)$ \\
\hline \multicolumn{3}{|l|}{ Occupation } \\
\hline Public sector employee† & 52 & $(32.5)$ \\
\hline Private sector employee & 27 & $(16.9)$ \\
\hline Housewife & 81 & $(50.6)$ \\
\hline \multicolumn{3}{|l|}{ Marital status } \\
\hline Married§ & 152 & $(95.0)$ \\
\hline Single & 8 & $(5.0)$ \\
\hline \multicolumn{3}{|l|}{ Smoking } \\
\hline Yes & 22 & $(13.8)$ \\
\hline No & 138 & $(86.2)$ \\
\hline Total & 160 & $(100.0)$ \\
\hline
\end{tabular}

*: Diploma, B.Sc. \& postgraduate degrees

$\dagger$ : Including retired

$\S$ : Including widowed and divorced 
Table 2: QOL scoring of diabetic patients in relation to age, gender, and monthly family income

QOL domains

\begin{tabular}{|c|c|c|c|c|}
\hline Variables & $\begin{array}{c}\text { Social } \\
\text { Mean }(95 \% \mathrm{Cl})\end{array}$ & $\begin{array}{c}\text { Physical } \\
\text { Mean }(95 \% \mathrm{Cl})\end{array}$ & $\begin{array}{l}\text { Psychological } \\
\text { Mean }(95 \% \mathrm{Cl})\end{array}$ & $\begin{array}{l}\text { Environmental } \\
\text { Mean }(95 \% \mathrm{Cl})\end{array}$ \\
\hline \multicolumn{5}{|c|}{ Age groups } \\
\hline $\begin{array}{l}<50 \text { years } \\
(n=65)\end{array}$ & $12.80(11.90-13.66)$ & $12.21(11.67-12.77)$ & $10.96(10.35-11.56)$ & $13.28(12.83-13.69)$ \\
\hline $\begin{array}{l}\geq 50 \text { years } \\
(n=95)\end{array}$ & $11.68(10.88-12.45)$ & $11.74(11.33-12.09)$ & $10.93(10.42-11.45)$ & $12.76(12.23-13.20)$ \\
\hline$P$ value & 0.067 & 0.156 & 0.962 & 0.109 \\
\hline \multicolumn{5}{|l|}{ Gender } \\
\hline $\begin{array}{l}\text { Male } \\
(n=68)\end{array}$ & $12.24(11.37-13.13)$ & $12.18(11.69-12.65)$ & $10.95(10.30-11.65)$ & $12.35(11.83-12.91)$ \\
\hline $\begin{array}{l}\text { Female } \\
(n=92)\end{array}$ & $12.06(11.31-12.27)$ & $11.75(11.31-12.17)$ & $10.94(10.46-11.41)$ & $13.43(13.03-13.83)$ \\
\hline$P$ value & 0.766 & 0.194 & 0.983 & 0.001 \\
\hline \multicolumn{5}{|c|}{ Monthly Family income } \\
\hline $\begin{array}{l}<\text { Enough } \\
(n=21)\end{array}$ & $9.27(7.67-10.67)$ & $11.02(10.14-11.48)$ & $10.06(9.13-11.06)$ & $12.09(10.96-13.21)$ \\
\hline $\begin{array}{l}\geq \text { Enough } \\
(n=139)\end{array}$ & $12.56(11.94-13.13)$ & $12.06(11.71-12.42)$ & $11.07(10.66-11.51)$ & $13.10(12.75-13.41)$ \\
\hline$P$ value & 0.001 & 0.031 & 0.088 & 0.039 \\
\hline
\end{tabular}

Note: The maximum score was 35 for the social domain, 30 for the psychological domain, 15 for the social domain and 40 for the environmental domain. 
QOL of diabetic patients had no significant statistical association with the duration and glycemic control of the disease in all the domains. Those who had checked their blood sugar regularly had better scores in the social domain $(P=0.036)$. Diabetic patients with complications showed significant $(P=0.013)$ lower scores in the psychological domain (Table 3).

Table 3: QOL scoring of diabetic patients by clinical variables of the patients.

\section{QOL domains}

Variables

$\begin{array}{cccc}\text { Social } & \text { Physical } & \text { Psychological } & \text { Environmental } \\ \text { Mean }(95 \% \mathrm{Cl}) & \text { Mean }(95 \% \mathrm{Cl}) & \text { Mean }(95 \% \mathrm{Cl}) & \text { Mean }(95 \% \mathrm{Cl})\end{array}$

Duration of the disease in years

$\begin{array}{lcccc}<10 & 12.09(11.36-12.76) & 12.05(11.65-12.44) & 11.03(10.51-11.52) & 13.05(12.67-13.42) \\ (n=108) & & & & \\ \geq 10 & 12.20(11.16-13.14) & 11.67(11.19-12.14) & 10.75(10.10-11.47) & 12.79(12.22-13.40) \\ (n=52) & 0.866 & 0.275 & 0.515 & 0.452\end{array}$

Frequent blood sugar testing

$\begin{array}{lcccc}\text { Yes }(\mathrm{n}=85) & 12.72(11.95-13.41) & 12.02(11.56-12.45) & 10.93(10.44-11.41) & 13.15(12.72-13.53) \\ \text { No }(\mathrm{n}=75) & 11.50(10.61-12.32) & 11.82(11.37-12.27) & 10.96(10.31-11.58) & 12.77(12.28-13.25) \\ P \text { value } & 0.036 & 0.532 & 0.942 & 0.249\end{array}$

Presence of complications

$\begin{array}{lcccc}\text { Yes }(\mathrm{n}=147) & 12.03(11.37-12.65) & 11.86(11.56-12.17) & 10.79(10.40-11.21) & 13.00(12.63-13.33) \\ \text { No }(n=13) & 13.23(11.52-14.66) & 12.70(11.07-14.23) & 12.61(1.61-13.61) & 12.61(11.36-13.82) \\ P \text { value } & 0.267 & 0.160 & 0.013 & 0.523\end{array}$

Glycemic control

$\begin{array}{lcccc}\text { Normal } & 12.2(11.41-12.99) & 11.96(11.31-12.04) & 11.13(10.65-11.66) & 13.06(12.66-13.47) \\ \text { Marginal } & 11.75(10.62-12.61) & 12.42(11.58-13.17) & 10.45(9.7-11.23) & 12.49(11.81-13.18) \\ \text { Poor } & 12.51(11.47-148) & 12.25(11.32-13.2) & 10.88(9.53-12.11) & 13.42(12.71-14.3) \\ P \text { value } & 0.732 & 0.139 & 0.372 & 0.221\end{array}$

Note: The maximum score was 35 for the social domain, 30 for the psychological domain, 15 for the social domain and 40 for the environmental domain. 


\section{Discussion}

Quality of life is an important aspect of diabetes because the poor quality of life leads to diminished self-care, which in turn leads to worsened glycemic control, increased risks for complications, and exacerbation of diabetes overwhelming in both the short run and the long run. Thus, it is apparent that quality of life issues are imperative and predict how well an individual would be able to handle his/ her disease and maintain long-term health and well-being. ${ }^{18}$ In this study, both age groups of diabetic patients had low scores in all QOL domains, with lower mean scores in the psychological domain, which may reflect the negative feelings, lower self-esteem, memory concentration, and body image/appearance. A study in Saudi Arabia revealed those diabetic patients above 50 years old had lower QOL than those below 50 years. ${ }^{19}$ However, another study in Erbil revealed that age was significantly affecting the overall QOL of diabetic patients. ${ }^{15}$ In our study, females reported a significantly higher score in the environmental domain only, while a study in India revealed higher mean scores of QOL in all the domains among females too. ${ }^{1}$ Another study in Saudi Arabia showed that females had significantly lower QoL scores. ${ }^{11}$ This may reflect the social structure of our community in issues related to the home environment, the educational and financial status of female diabetic patients.QOL of diabetic patients with low monthly family income had lower scores than those with enough or more than enough family income, in the social, psychological and environmental domains. Studies in Iran and Gaza strip revealed that the effect of diabetes on QOL was severe, particularly among females and older individuals more than 50 years of age and those with low socioeconomic status. ${ }^{20,21}$ This may reflect the real socio-economic status of those with insufficient family income who could not take the necessary measures to prevent complications of the disease and could not reflect on different issues related to their well-being including reducing pain, discomfort, negative feelings and work satisfaction. QOL of diabetic patients in this study had no significant association with the duration and glycemic control of the disease in all the domains. A study in Iran had revealed that longer disease duration was correlated with extreme problems in most domains of QOL. ${ }^{20}$ However, a study in Portugal showed that "longer disease duration was correlated with worse physical functioning, physical role, emotional role, and mental health," ${ }^{22}$ and a study in Romania showed that emotional problems led to role restrictions and correlated with disease duration. ${ }^{23}$ This may indicate that our diabetic patients are aware of the course of their disease and how the longer duration of the disease could contribute to more physical and psychological role limitation, in case the control and preventive measures were not applied on time. Those who had checked their blood sugar regularly had better scores in the social domain. A study in Bangladesh demonstrated that around $90 \%$ of all diabetic patients did not check their sugar levels frequently had faced many clinical problems. ${ }^{24} \mathrm{~A}$ study in Egypt showed that $38.6 \%$ of the patients had uncontrolled diabetes based on $\mathrm{HbA} 1 \mathrm{c}$ levels with lower health-related QOL scores, ${ }^{25}$ and a study in Oman showed that patients with less than $8 \% \mathrm{HbA} 1 \mathrm{c}$ levels showed a significant better QOL. ${ }^{26}$ In our study, diabetic patients with complications showed a significantly lower score in the psychological domain. In Singapore, a study demonstrated that lower QOL was correlated with some associated clinical problems and complications, ${ }^{27}$ and a Serbian study showed that patients with associated clinical problems had worse scores in overall QOL domains. ${ }^{28}$ This may reflect the nature of the disease among the study population that might lead to negative feelings, poor concentration and adverse effects on mental health status. This study, however, had several limitations. First, this 
was a cross-sectional study, which is capable of identifying relations, without identifying causation. Generalization of the findings to the whole population could be imperfect because the sample was selected from a specialized diabetic center and could not represent the true diabetic patients.

\section{Conclusion}

All domains of QOL were affected by the disease. Both genders of all ages of the patients had reported lower domain scores, and there was no clear, consistent statistical association between clinical characteristics of the patients and the QOL of various domains.

\section{Competing interests}

The authors declare that they have no competing interests.

\section{References}

1. Somappa HK, Venkatesha M, Prasad R. Quality of life assessment among type 2 diabetic patients in rural tertiary center. Int J Med Sci Public Health 2014; 3:415-7.

2. Wild S, Rojlik G, Green A, Sicree R, King H. Global prevalence of diabetes, estimates for the year 2000 and projections for 2030.Diabetes Care 2004; 27:1047-53.

3. Shaw JE, Sicree RA, Zimmet PZ. Global estimates of the prevalence of diabetes for 2010 and 2030. Diabetes Res Clin Pract 2010; 87:4-14.

4. Awad A, Dalle H, Enlund H. Diabetic patients' knowledge of therapeutic goals in Kuwait. Med Princ Pract 2011; 20:118-23.

5. Solli O, Stavem K, Kristiansen IS. Health-related quality of life in diabetes: The associations of complications with EQ-5D scores. Health Qual Life Outcomes 2010; 8:1-8.

6. Saleh MS, Alwahedi Z, Taher M, Mostafa A, Hashim M, Almahdi H. Quality of life predictors and glycemic control among type 2 diabetic patients attending primary health care centers in Qatar. Primary Health Care 2016; 6:1-5.

7. Sherif S, Sumpio BE. Economic development and diabetes prevalence in MENA countries: Egypt and Saudi Arabia comparison. World J Diabetes 2015; 6:304-11.

8. Awad A, Dalle H, Enlund H. Diabetic patients' knowledge of therapeutic goals in Kuwait. Med Princ Pract 2011; 20:118-23.

9. Korff MV, Katon W, Lin EH, Simon G, Clechanowskip, Ludman E, et al. Work disability among individuals with diabetes. Diabetes Care 2005; 28:1326-31.
10. Dhippayom, Krass I. Supporting selfmanagement of type 2 diabetes: is there a role for the community pharmacist? Patient Prefer Adherence 2015; 9:1085-92.

11. Al- Shehri AH, Taha AZ, Bahnassy AA, Salah M. Health-related quality of life in type 2 diabetic patients. Ann Saudi Med 2008; 28:352-60.

12. Al- Shehri FS. Quality of Life among Saudi diabetics. J Diabetes Mellitus 2014; 4:225-31.

13. Oguntibeju OO, Odunaiya N, Oladipo B, Truter EJ. Health behavior and quality of life of patients with type 2 diabetes attending selected hospitals in South Western Nigeria. West Indian Med J 2012; 6:619-26.

14. Hussein RN, Khther SA, Al-Hadithi TS. Impact of diabetes on physical and psychosocial aspects of quality of life of diabetic patients in Erbil city, Iraq. Duhok Med J 2010; 4:49-59.

15. Hussein RN, Khther SA, Al-Hadithi TS. Association of certain sociodemographic and clinical characteristics of diabetic patients with quality of life. Zanco J Med Sci 2011; 15:35-42.

16. Iraq, the population of the provinces and province capitals of the Republic of Iraq. (Accessed March 12, 2017 at http://www.citypopulation.de//raq.html).

17. WHO. WHOQOL-BREF introduction, administration, scoring and generic version of the assessment 1996. (Accessed March 12, 2017 at http://www.who.int/mental_health/media/ en/76.pdf).

18. Jain V, Shivkumar S, Gupta O. Health-Related Quality of Life (Hr-Qol) in Patients with Type 2 Diabetes Mellitus. N Am J Med Sci 2014; 6:96101.

19. Al Hayek AA, Robert AA, Al Saeed A, Alzaid AA, Al Sabaan FS. Factors associated with health-related quality of life among Saudi patients with type 2 diabetes mellitus: A cross-sectional survey. Diabetes Metab J 2014; 38:220-9.

20. Javanbakht $M$, Abolhasani $F$, Mashayekhi A, Baradaran HR, Noudeh YJ. Health-related quality of life in patients with type 2 Diabetes Mellitus in Iran: A National Survey 2012. PloSONE 2012; $7: 1-9$.

21. Eljedi A, Mikolajczyk RF, Kraemer A, Laaser U. Health-related quality of life in diabetic patients and controls without diabetes in refugee camps in the Gaza Strip: a cross-sectional study. BMC Public Health 2006; 6:1-7.

22. Sepúlveda E, Poínhos R, Constante $M$, Pais-Ribeiro J, Freitas $P$, Carvalho D. Health-related quality of life in type 1 and type 2 diabetic patients in a Portuguese central public hospital. Diabetes. Diabetes Metab Syndr Obes 2015; 8:219-26.

23. Porojan M, Ponta L, Dumitrascu DL. Assessing health-related quality of life in diabetic patients. Rom J Intern Med 2012; 50:27-31.

24. Shariful-Islam SM, Lechner A, Ferrari U, Froeschl G, Niessen LW, Seissler J, et al. Social 
and economic impact of diabetics in Bangladesh: protocol for a case-control study. BMC Public Health 2013; 13:2-9.

25. AbdElaziz KM, Fatma M Nour-Eldin FM, Momen MA, Damaty SI. Assessment of health-related quality of life among diabetic patients in Al Gharbia Governorate, Egypt using COOP/ WONCA charts. Egypt J Community Med 2014; 32:49-56.

26. Al- Maskari MY, Al- Shookri AO, Al- Adawi SH, Lin KG. Assessment of quality of life in patients with type 2 diabetes mellitus in Oman. Saudi Med J 2011; 32:1285-90.

27. Quah J, Luo N, Ng WY, How CH, Tay EG. Health -related quality of life is associated with diabetic complications, but not with short-term diabetic control in primary care. Ann Acad Med Singapore 2011; 40:276-86.

28. Spasić A, Radovanović RV, Đorđević AC, Stefanović N, Cvetković T. Quality of life in type 2 diabetic patients. Acta Medica Mediance 2014; 3:193-200. 